\title{
Compared with the intake of commercial vegetable juice, the intake of fresh fruit and komatsuna (Brassica rapa L. var. perviridis) juice mixture reduces serum cholesterol in middle-aged men: a randomized controlled pilot study
}

Izumi Aiso ${ }^{1 \dagger}$, Hiroko Inoue ${ }^{1,2+}$, Yukiko Seiyama ${ }^{2}$ and Toshiko Kuwano ${ }^{1,2^{*}}$

\begin{abstract}
Background: Vegetables and fruits are rich in vitamins, minerals and, dietary fiber and contribute to the prevention and improvement of obesity and metabolic syndrome. However, inadequate intake of vegetable and fruit is a concern in Japan.

We therefore produced a juice mixture of fresh fruit and komatsuna (Brassica rapa L. var. perviridis: B. rapa) with the aim to investigate the effects of this juice mixture on anthropometric data, blood parameters, and dietary intake differences.

Methods: This study was performed as a single blind and randomized controlled trial. Subjects were 16 men (mean age, $46.4 \pm 7.1$ years), and they were divided into two groups (control group and intervention group). The intervention group consumed the juice mixture of fresh fruit and B. rapa. The control group consumed commercial vegetable juice. Subjects consumed juice twice a day throughout the weekday, for 4 weeks. We prepared both juices with an equivalent energy balance.

Results: Weight and body mass index (BMI) of the control group after 4 weeks were significantly increased compared with baseline values. Serum total cholesterol (T-Chol) and low-density lipoprotein cholesterol (LDL-Chol) of the intervention group after 4 weeks were significantly reduced compared with baseline values. Furthermore, intake of total vegetables and fruits were significantly increased compared with baseline values in both groups.

Conclusions: Both vegetable juices contributed to improved intake of total vegetables and fruit. Compared with the intake of commercial vegetable juice, the intake of fresh fruit and B. rapa juice is highly effective in reducing serum cholesterol. Short-term intake of fresh fruit and B. rapa juice was shown to enhance cholesterol metabolism.
\end{abstract}

Keywords: Vegetable, Fruit, Serum cholesterol, Middle-aged men, Metabolic syndrome

\footnotetext{
*Correspondence: kuwano@u-shizuoka-ken.ac.jp

${ }^{\dagger}$ Equal contributors

'Department of Food and Nutritional Sciences and Environmental Health

Sciences, Graduate School of Integrated Pharmaceutical and Nutritional

Sciences, University of Shizuoka, 52-1 Yada, Suruga-ku, 422-8526, Shizuoka,

Japan

${ }^{2}$ School of Food and Nutritional Sciences, University of Shizuoka, Shizuoka,

Japan
} 


\section{Background}

An increase in LDL-Chol concentration is a risk factor for arteriosclerosis. Arteriosclerosis is closely linked to increases in the incidence of coronary artery disease, stroke, and arteriosclerosis obliterans. A recent study indicates that a high LDL-Chol concentration increases the risk of arteriosclerosis, and a high T-Chol concentration increases the risk of coronary artery disease [1].

The consumption of vegetable and fruit improves lipid composition in blood. Guimares reported that intake of eggplant (Solanum melongena) infusion significantly reduced the blood concentrations of T-Chol, LDL-Chol, and apolipoprotein B in hypercholesterolemia subjects [2]. Futhermore, in a cohort study of 4466 subjects, Djoussé reported that consumption of fruits and vegetables is inversely related to LDL-Chol [3].

Moreover, previous studies show an association between fruit and vegetable consumption and coronary artery disease, ischemic heart disease, and cerebrovascular disease. Increasing the consumption of fruit and vegetables reduces the risk of coronary artery disease, stroke, and hypertension [4]. Compared with people who consume vegetables and fruits once or less a day, those who consume vegetables and fruits thrice or more a day have lower stroke incidence, stroke mortality, ischemic heart disease mortality, and cardiovascular disease mortality [5].

High consumption of vegetables and fruits may have effects on blood lipid metabolism and reduce the risk of diseases stemming from arteriosclerosis.

In Japan, "Healthy Japan 21" was developed as a prophylaxis of life-style related diseases by Health, Labour and the Welfare Ministry in 2000 [6]. Healthy Japan 21 promotes a vegetable intake of more than $350 \mathrm{~g} /$ day, green and yellow vegetable intake of more than $120 \mathrm{~g} /$ day, and fruit intake of $200 \mathrm{~g} /$ day. However, these goals may still be unattainable in all life stages [6].

To improve the current situation, we need to take some drastic measures. With such an aim, we produced fresh of fruit and B. rapa juice mixture as a means of providing easy intake of vegetable and fruit.

There are reports that daily intake of commercial vegetable juice increases dietary vegetable intake $[7,8]$. However, reports of intervention studies using fresh fruit and vegetable juice are few [9-11].

We conducted an intervention study to investigate whether daily intake of a juice mixture from fresh fruit and $B$. rapa would affect anthropometric data, blood parameters, and dietary intake.

\section{Results}

\section{Characteristics of subjects}

Characteristics of the study subjects are shown in Table 1. The mean anthropometric data of the study subjects did not exceed the reference value for metabolic syndrome.
Table 1 Characteristics of subjects

\begin{tabular}{lc}
\hline & Mean \pm S.D. \\
\hline Age (years) & $46.6 \pm 7.1$ \\
Height $(\mathrm{cm})$ & $172.3 \pm 5.7$ \\
Weight $(\mathrm{kg})$ & $73.3 \pm 16.8$ \\
Body fat percentage $(\%)$ & $23.2 \pm 8.1$ \\
Body mass index $(\mathrm{kg} / \mathrm{m} 2)$ & $24.6 \pm 5.2$ \\
Waist Circumference $(\mathrm{cm})$ & $87.4 \pm 13.6$ \\
Systolic blood pressure $(\mathrm{mmHg})$ & $126 \pm 16$ \\
Diastolic blood pressure $(\mathrm{mmHg})$ & $79 \pm 12$ \\
\hline Data shows mean \pm S.D. &
\end{tabular}

However, BMI and waist circumference tended to be moderately high.

Nutrient components of commercial vegetable juice and fresh fruit and $B$. rapa juice mixture

Nutrient components of both juices are shown in Table 2. Nutrition components of commercial vegetable juice (100 g) were as follows: energy, $48 \mathrm{kcal}$; potassium, $173 \mathrm{mg}$; and $\beta$-carotene, equivalents $2628 \mu \mathrm{g}$. In contrast, nutrition components of fresh fruit and B. rapa juice mixture (100 g) were as follows: energy, $44 \mathrm{kcal}$; potassium, $180 \mathrm{mg}$; and $\beta$-carotene equivalents, $360 \mu \mathrm{g}$. Volume of protein, fat, carbohydrate, sodium, iron, folate, vitamin $C$, and dietary fiber are shown in Table 2.

\section{Anthropometric data}

Anthropometric data of both groups are shown in Table 3. Weight and BMI after 4 weeks in the control group were significantly increased compared with baseline values (weight:

Table 2 Nutrient components of commercial vegetable juice and fresh fruit and $B$. rapa juice mixture

\begin{tabular}{lcc}
\hline & $\begin{array}{c}\text { Commercial } \\
\text { vegetable juice }\end{array}$ & $\begin{array}{c}\text { Fresh fruit and B. rapa } \\
\text { juice }\end{array}$ \\
\hline Enixture
\end{tabular}

※1) Nutritional labeling of commercial vegetable juice.

$※ 2$ ) Analysis values by Japan Inspection Association of Food and Food Industry Environment.

Abbreviation: B. rapa Brassica rapa L. var. perviridis. 
Table 3 Change of anthropometric data

\begin{tabular}{|c|c|c|c|c|c|c|}
\hline & \multicolumn{2}{|c|}{ Control group $(n=8)$} & \multirow[b]{3}{*}{ p } & \multicolumn{2}{|c|}{ Intervention group $(n=8)$} & \multirow[b]{3}{*}{$p$} \\
\hline & Baseline & After 4 weeks & & Baseline & After 4 weeks & \\
\hline & Mean \pm S.D. & Mean \pm S.D. & & Mean \pm S.D. & Mean \pm S.D. & \\
\hline Height (cm) & $172.3 \pm 6.7$ & $172.3 \pm 6.7$ & 0.735 & $172.4 \pm 4.9$ & $172.4 \pm 4.7$ & 0.611 \\
\hline Weight (kg) & $70.7 \pm 14.1$ & $71.9 \pm 13.8$ & $0.017^{*}$ & $76.0 \pm 19.7$ & $76.3 \pm 19.4$ & 0.362 \\
\hline BFP (\%) & $24.3 \pm 9.5$ & $24.9 \pm 9.6$ & 0.484 & $22.1 \pm 7.0$ & $23.1 \pm 7.5$ & 0.069 \\
\hline $\mathrm{BMI}(\mathrm{kg} / \mathrm{m} 2)$ & $23.8 \pm 4.9$ & $24.2 \pm 4.8$ & $0.042^{*}$ & $25.4 \pm 5.6$ & $25.5 \pm 5.6$ & 0.259 \\
\hline Waist circumference & $86.6 \pm 12.9$ & $86.5 \pm 12.8$ & 0.932 & $88.3 \pm 15.2$ & $88.2 \pm 15.2$ & 0.326 \\
\hline Systolic blood pressure $(\mathrm{mmHg})$ & $125 \pm 13$ & $128 \pm 15$ & 0.327 & $126 \pm 19$ & $133 \pm 17$ & 0.050 \\
\hline Diastolic blood pressure $(\mathrm{mmHg})$ & $79 \pm 12$ & $80 \pm 10$ & 0.147 & $79 \pm 14$ & $82 \pm 12$ & 0.237 \\
\hline
\end{tabular}

Data shows mean \pm S.D.

Abbreviations: BFP Body fat percentage, BMI Body mass index.

Baseline vs After 4 weeks, Wilcoxon signed rank test, ${ }^{*} \mathrm{p}<0.05$.

$70.7 \pm 14.1$ vs $71.9 \pm 13.8 \mathrm{~kg}, p=0.017$; BMI: $23.8 \pm 4.9$ vs $24.2 \pm 4.8 \mathrm{~kg} / \mathrm{m}^{2}, p=0.042$ ). In contrast, there were no significant differences in the intervention group.

\section{Blood parameters}

Blood parameters of both groups are shown in Table 4 . T-Chol and LDL-Chol after 4 weeks in the intervention group were significantly decreased compared with baseline values (T-Chol: $220 \pm 28$ vs $211 \pm 27 \mathrm{mg} / \mathrm{dL}, p=0.017$; LDL-Chol: $143 \pm 27$ vs $134 \pm 23 \mathrm{mg} / \mathrm{dL}, p=0.017)$.

\section{Energy and nutrition intake}

Energy and nutrition intake of both groups are shown in Table 5. Potassium intake after 4 weeks in both groups were significantly increased compared with baseline values (control group: $2,550 \pm 1,105$ vs $3,049 \pm 1,068 \mathrm{mg}$, $p=0.012$; intervention group: $2,815 \pm 978$ vs $3,486 \pm$ $766 \mathrm{mg}, p=0.017)$. $\beta$-carotene equivalent intake after 4 weeks in the intervention group was significantly increased compared with the baseline value $(3,815 \pm 2,357$ vs $4,795 \pm 1,881 \mu \mathrm{g}, p=0.036$ ). Magnesium intake after 4 weeks in the intervention group tended to increase compared with the baseline value $(286 \pm 69$ vs $312 \pm$ $64 \mathrm{mg}, p=0.069$ ).

Vitamin $C$ intake after 4 weeks in both groups were increased compared with baseline values (control group: $101.6 \pm 50.9$ vs $188.0 \pm 67.0 \mathrm{mg}, p=0.012$; intervention group: $121.2 \pm 67.3$ vs $223.9 \pm 46.9 \mathrm{mg}, p=0.012$ ).

Table 4 Change of blood parameter

\begin{tabular}{|c|c|c|c|c|c|c|}
\hline & Contr & $p(n=8)$ & & Interven & oup $(n=8)$ & \\
\hline & Baseline & After 4 weeks & & Baseline & After 4 weeks & \\
\hline & Mean \pm S.D. & Mean \pm S.D. & p & Mean \pm S.D. & Mean \pm S.D. & $p$ \\
\hline Glucose (mg/dL) & $95 \pm 6$ & $96 \pm 6$ & 0.359 & $100 \pm 7$ & $96 \pm 10$ & 0.106 \\
\hline Hemoglobin A1c (\%) & $5.3 \pm 0.3$ & $5.3 \pm 0.3$ & 0.589 & $5.7 \pm 0.8$ & $5.6 \pm 0.4$ & 0.526 \\
\hline Triacylglycerol (mg/dL) & $121 \pm 82$ & $160 \pm 118$ & 0.080 & $122 \pm 47$ & $121 \pm 49$ & 1.000 \\
\hline Free fatty acid $(\mu \mathrm{Eq} / \mathrm{L})$ & $586 \pm 526$ & $451 \pm 132$ & 0.779 & $497 \pm 184$ & $379 \pm 54$ & 0.069 \\
\hline T-Chol (mg/dL) & $210 \pm 38$ & $210 \pm 33$ & 0.833 & $220 \pm 28$ & $211 \pm 27$ & $0.017^{*}$ \\
\hline HDL-Chol (mg/dL) & $50 \pm 12$ & $51 \pm 15$ & 0.570 & $53 \pm 15$ & $53 \pm 13$ & 0.799 \\
\hline LDL-Chol (mg/dL) & $136 \pm 36$ & $127 \pm 23$ & 0.262 & $143 \pm 27$ & $134 \pm 23$ & $0.017^{*}$ \\
\hline Insulin $(\mu \mathrm{l} \mathrm{U} / \mathrm{mL})$ & $8.72 \pm 11.40$ & $10.80 \pm 14.77$ & 0.161 & $7.39 \pm 8.42$ & $9.42 \pm 13.03$ & 0.327 \\
\hline Vitamin $C(\mu \mathrm{g} / \mathrm{mL})$ & $2.38 \pm 1.14$ & $1.82 \pm 0.83$ & 0.441 & $1.76 \pm 0.49$ & $1.80 \pm 0.44$ & 0.726 \\
\hline Leptin (pg/mL) & $236 \pm 301$ & $214 \pm 255$ & 0.401 & $129 \pm 99$ & $161 \pm 185$ & 1.000 \\
\hline Adiponectin $(\mu \mathrm{g} / \mathrm{mL})$ & $13.2 \pm 13.8$ & $13.3 \pm 13.9$ & 1.000 & $8.2 \pm 5.9$ & $8.3 \pm 5.7$ & 0.866 \\
\hline HOMA-IR & $2.10 \pm 2.83$ & $2.69 \pm 3.87$ & 0.655 & $1.92 \pm 2.38$ & $2.44 \pm 3.71$ & 0.144 \\
\hline Arteriosclerotic Index & $3.49 \pm 1.58$ & $3.55 \pm 1.87$ & 0.779 & $3.48 \pm 1.59$ & $3.16 \pm 1.05$ & 0.327 \\
\hline
\end{tabular}

Data shows mean \pm S.D.

Abbreviation: T-Chol Total cholesterol, HDL-Chol High-density lipoprotein cholesterol, LDL-Chol Low-density lipoprotein cholesterol, HOMA-IR Homeostasis model of assessment of insulin resistance.

Baseline vs After 4 weeks, Wilcoxon signed rank test, ${ }^{*} \mathrm{p}<0.05$. 
Table 5 Change of energy and nutrition intakes

\begin{tabular}{|c|c|c|c|c|c|c|}
\hline & Control & $p(n=8)$ & & Intervent & oup $(n=8)$ & \\
\hline & Baseline & After 4 weeks & & Baseline & After 4 weeks & \\
\hline & Mean \pm S.D. & Mean \pm S.D. & $p$ & Mean \pm S.D. & Mean \pm S.D. & $p$ \\
\hline Energy (kcal) & $1,829 \pm 401$ & $1,955 \pm 460$ & 0.327 & $2,190 \pm 293$ & $2,247 \pm 364$ & 0.401 \\
\hline Protein (g) & $73.1 \pm 24.8$ & $74.9 \pm 26.7$ & 0.484 & $77.3 \pm 17.0$ & $76.7 \pm 16.7$ & 0.889 \\
\hline Fat (g) & $52.3 \pm 15.0$ & $50.1 \pm 16.1$ & 0.484 & $69.8 \pm 14.7$ & $61.0 \pm 15.9$ & 0.069 \\
\hline Carbohydrate (g) & $248.0 \pm 52.5$ & $291.9 \pm 77.0$ & 0.327 & $288.0 \pm 26.3$ & $325.7 \pm 54.0$ & $0.025^{*}$ \\
\hline Sodium (mg) & $4,251 \pm 1,233$ & $4,576 \pm 1,519$ & 0.123 & $4,339 \pm 918$ & $4,564 \pm 868$ & 0.401 \\
\hline Potassium (mg) & $2,550 \pm 1,105$ & $3,049 \pm 1,068$ & $0.012^{*}$ & $2,815 \pm 978$ & $3,486 \pm 766$ & $0.017^{*}$ \\
\hline Calcium (mg) & $611 \pm 249$ & $572 \pm 283$ & 0.401 & $610 \pm 190$ & $608 \pm 159$ & 0.674 \\
\hline Magnesium (mg) & $266 \pm 99$ & $278 \pm 101$ & 0.263 & $286 \pm 69$ & $312 \pm 64$ & 0.069 \\
\hline Phosphorus (mg) & $1,105 \pm 392$ & $1,126 \pm 426$ & 0.575 & $1,172 \pm 282$ & $1,173 \pm 258$ & 0.889 \\
\hline Iron (mg) & $8.4 \pm 3.5$ & $8.9 \pm 3.4$ & 0.123 & $9.0 \pm 2.6$ & $9.8 \pm 2.5$ & 0.093 \\
\hline Zinc (mg) & $8.7 \pm 2.8$ & $8.9 \pm 2.9$ & 0.484 & $9.1 \pm 1.8$ & $8.9 \pm 1.9$ & 0.833 \\
\hline Manganese (mg) & $3.5 \pm 1.1$ & $3.5 \pm 1.1$ & 0.401 & $3.6 \pm 0.9$ & $3.4 \pm 1.0$ & 0.208 \\
\hline$\beta$-carotene equivalent $(\mu \mathrm{g})$ & $3,926 \pm 2,674$ & $3,945 \pm 1,639$ & 0.674 & $3,815 \pm 2,357$ & $4,795 \pm 1,881$ & $0.036^{*}$ \\
\hline Retinol equivalent $(\mu \mathrm{g})$ & $753 \pm 555$ & $808 \pm 471$ & 0.779 & $929 \pm 459$ & $855 \pm 370$ & 0.674 \\
\hline a-tocopherol (mg) & $7.0 \pm 2.5$ & $7.6 \pm 2.4$ & 0.161 & $8.9 \pm 2.9$ & $9.7 \pm 2.4$ & 0.161 \\
\hline Vitamin C (mg) & $101.6 \pm 50.9$ & $188.0 \pm 67.0$ & $0.012^{*}$ & $121.2 \pm 67.3$ & $223.9 \pm 46.9$ & $0.012^{*}$ \\
\hline Saturated fat (g) & $13.6 \pm 3.9$ & $13.2 \pm 5.0$ & 0.674 & $18.7 \pm 3.5$ & $16.4 \pm 3.9$ & 0.093 \\
\hline Monounsaturated fat (g) & $18.4 \pm 5.4$ & $17.7 \pm 5.4$ & 0.575 & $25.0 \pm 5.3$ & $21.5 \pm 6.1$ & 0.093 \\
\hline Polyunsaturated fat (g) & $13.5 \pm 4.0$ & $12.4 \pm 4.0$ & 0.263 & $17.2 \pm 4.1$ & $14.9 \pm 3.8$ & 0.069 \\
\hline Cholesterol (mg) & $417 \pm 205$ & $424 \pm 193$ & 0.889 & $434 \pm 127$ & $441 \pm 153$ & 0.779 \\
\hline Total dietary fiber (g) & $12.2 \pm 5.2$ & $11.6 \pm 4.0$ & 0.484 & $13.6 \pm 3.8$ & $14.1 \pm 3.9$ & 0.484 \\
\hline Soluble dietary fiber (g) & $3.1 \pm 1.5$ & $3.2 \pm 1.3$ & 0.673 & $3.5 \pm 1.1$ & $3.9 \pm 1.1$ & 0.093 \\
\hline Insoluble dietary fiber (g) & $8.7 \pm 3.5$ & $8.1 \pm 2.6$ & 0.263 & $9.6 \pm 2.5$ & $9.6 \pm 2.6$ & 1.000 \\
\hline Sodium chloride equivalent (g) & $10.8 \pm 3.1$ & $11.6 \pm 3.8$ & 0.123 & $10.9 \pm 2.3$ & $11.5 \pm 2.2$ & 0.401 \\
\hline
\end{tabular}

Data shows mean \pm S.D.

Baseline vs After 4 weeks, Wilcoxon signed rank test, ${ }^{*} \mathrm{p}<0.05$.

\section{Food intake}

Food intakes of both groups are shown in Table 6. Total vegetable and fruit intake after 4 weeks in both groups were increased compared with baseline values (total vegetable value of control group: $246.0 \pm 149.0$ vs $324.6 \pm$ $121.3 \mathrm{~g}, p=0.012$; total vegetable value of intervention group: $280.7 \pm 168.3$ vs $396.9 \pm 121.5 \mathrm{~g}, p=0.012$; fruits value of control group: $70.1 \pm 63.0$ vs $438.3 \pm 181.3 \mathrm{~g}$, $p=0.017$; fruits value of intervention group: $106.2 \pm 91.8$ vs $524.0 \pm 44.2 \mathrm{~g}, p=0.012$ ). Furthermore, green and yellow vegetables intake after 4 weeks in both groups were increased compared with baseline values (control group: $105.5 \pm 71.8$ vs $177.8 \pm 60.4 \mathrm{~g}, p=0.012$; intervention group: $108.1 \pm 78.5$ vs $225.2 \pm 54.6 \mathrm{~g}, p=0.012$ ).

\section{Discussion}

We performed an intervention pilot study on the effects of short-term intake of either a juice mixture of fresh fruit and B. rapa or commercial vegetable juice in middle-aged men. The aim of the present study was to compare the effects of a juice mixture of fresh fruit and $B$. rapa with those of commercial vegetable juice on anthropometric data, blood parameters, and dietary intake.

T-Chol and LDL-Chol after 4 weeks in the intervention group were significantly decreased compared with baseline values. However, T-Chol and LDL-Chol after 4 weeks in the control group were unchanged compared with baseline values. Short-term intake of juice mixture of fresh fruit and B. rapa is thought to enhance cholesterol metabolism. Subjects with hypercholesterolemia who were given two cans of a beverage of mixed green vegetable and fruit beverage (containing broccoli and cabbage for 12 weeks) had reduced LDL-Chol after 3 weeks compared with baseline values [12]. Our results showed a similar result, which infers that reductions in LDL-Chol may involve increases in fecal bile acid by S-methylcysteine sulfoxide contained in Brassica vegetables [12]. 
Table 6 Change of food intake

\begin{tabular}{|c|c|c|c|c|c|c|}
\hline & Contrc & $\mathrm{up}(\mathrm{n}=8)$ & & Intervent & roup $(n=8)$ & \\
\hline & Baseline & After 4 weeks & & Baseline & After 4 weeks & \\
\hline & Mean \pm S.D. & Mean \pm S.D. & $\mathbf{p}$ & Mean \pm S.D. & Mean \pm S.D & p \\
\hline Cereals (g) & $459.1 \pm 125.5$ & $490.8 \pm 190.9$ & 0.735 & $456.9 \pm 102.6$ & $428.8 \pm 129.7$ & 0.310 \\
\hline Potatoes (g) & $53.2 \pm 38.6$ & $47.0 \pm 23.2$ & 0.600 & $52.3 \pm 46.0$ & $48.4 \pm 16.3$ & 0.600 \\
\hline Nuts and pulses (g) & $87.0 \pm 57.8$ & $72.1 \pm 57.3$ & 0.237 & $79.3 \pm 34.8$ & $73.4 \pm 37.9$ & 0.600 \\
\hline Total vegetables (g) & $246.0 \pm 149.0$ & $324.6 \pm 121.3$ & $0.012^{*}$ & $280.7 \pm 168.3$ & $396.9 \pm 121.5$ & $0.012^{*}$ \\
\hline Green and yellow vegetables ( $\mathrm{g}$ ) & $105.5 \pm 71.8$ & $177.8 \pm 60.4$ & $0.012^{*}$ & $108.1 \pm 78.5$ & $225.2 \pm 54.6$ & $0.012^{*}$ \\
\hline Other vegetables $(\mathrm{g})$ & $140.6 \pm 78.9$ & $146.8 \pm 74.8$ & 0.484 & $172.6 \pm 95.1$ & $171.7 \pm 68.9$ & 0.674 \\
\hline Fruits (g) & $70.1 \pm 63.0$ & $438.3 \pm 181.3$ & $0.017^{*}$ & $106.2 \pm 91.8$ & $524.0 \pm 44.2$ & $0.012^{*}$ \\
\hline Fish and shellfish (g) & $75.4 \pm 56.9$ & $74.9 \pm 53.5$ & 0.866 & $71.1 \pm 31.5$ & $75.3 \pm 31.5$ & 0.674 \\
\hline Meat (g) & $65.6 \pm 30.3$ & $82.6 \pm 44.5$ & 0.263 & $77.8 \pm 29.1$ & $72.5 \pm 27.1$ & 0.398 \\
\hline Eggs (g) & $51.5 \pm 32.0$ & $53.2 \pm 27.5$ & 0.798 & $41.7 \pm 24.7$ & $48.6 \pm 26.7$ & 0.310 \\
\hline Dairy products (g) & $191.8 \pm 103.1$ & $156.4 \pm 129.0$ & 0.176 & $174.7 \pm 82.8$ & $150.4 \pm 55.0$ & 0.176 \\
\hline Fat and oil (g) & $10.4 \pm 6.5$ & $10.3 \pm 6.0$ & 0.735 & $14.6 \pm 5.3$ & $12.9 \pm 4.3$ & 0.575 \\
\hline Confectionery (g) & $28.8 \pm 23.0$ & $20.1 \pm 17.7$ & 0.263 & $73.6 \pm 42.1$ & $64.7 \pm 34.0$ & 0.463 \\
\hline Beverage preference (g) & $621.4 \pm 325.3$ & $508.8 \pm 337.3$ & 0.069 & $850.0 \pm 406.0$ & $790.7 \pm 281.9$ & 0.401 \\
\hline
\end{tabular}

Data shows mean \pm S.D.

Baseline vs After 4 weeks, Wilcoxon signed rank test, ${ }^{*} \mathrm{p}<0.05$.

Potassium and Vitamin C intake after 4 weeks in both groups were increased compared with baseline values. $\beta$-carotene equivalent intake after 4 weeks in the intervention group was increased compared with baseline values. These findings are related to reports on mineral and lipids metabolism from previous studies. Potassium increases activity of LPL through high insulin concentrations $[8,13,14]$. Magnesium is the essential mineral for the enzyme that is involved in lipid metabolism, capable of decreasing T-Chol concentrations $[15,16]$. Magnesium intake after 4 weeks in the intervention group tended to increase compared with the baseline value in the present study. Furthermore, $\beta$-carotene reduces the activity of 3-hydroxy-3-methylglutaryl coenzyme A reductase and inhibits the synthesis of cholesterol $[17,18]$.

Antioxidant vitamins are related to lipid metabolism. LDL-Chol binds to the LDL receptor and is translocated into the cell. However, when LDL-Chol is oxidized, receptor binding affinity is decreased. Antioxidant vitamins prevent oxidation of LDL-Chol and supports lipid metabolism [11]. Vitamin C intake after 4 weeks in both groups were significantly increased compared with baseline values in the present study. Furthermore, $\beta$-carotene equivalent intake after 4 weeks in the intervention group was increased compared with the baseline value. These results show that intake of fresh fruit and $B$. rapa juice mixture increased antioxidant vitamins.

Weight and BMI after 4 weeks in the control group were significantly increased compared with baseline values in the present study. However, there was no difference in dietary energy after 4 weeks compared with the baseline value. We used brief and self-administered diet history questionnaires (BDHQ) as a dietary survey method in our study. BDHQ has been used and validated in many studies [19-21]. However, BDHQ is not as accurate as weighed dietary records. Hence, it was not clear whether dietary changes in the present study caused the increases in weight and BMI in the control group.

Commercial juice contains 7 times more carotene than the juice mixture comprising fresh fruit and B. rapa. However, $\beta$-carotene intake in the control group did not change from baseline. BDHQ does not enable the identification of the types of vegetables included in the vegetable juice. Therefore, the fresh fruit and B. rapa juice mixture and commercial juice were calculated as vegetable juice. For these reasons, we were not able to confirm an effect of the $\beta$-carotene equivalent of the commercial juice using the dietary survey.

The limitation of the present study is the short-term intervention. We also did not have a control group that did not drink juice. In future, we will perform a longterm intervention of fresh fruit and B. rapa juice mixture, and also examine the effects on lipid metabolism.

\section{Conclusions}

We performed an intervention pilot study to compare the effects of a short-term intake of fresh fruit and $B$. rapa juice mixture with those of commercial vegetable juice in middle-aged men. 
Regular consumption of vegetable juices contributed to increased intake of total vegetables and fruits. Interestingly, compared with the intake of commercial vegetable juice, the intake of fresh fruit and B. rapa juice mixture is highly effective in reducing serum cholesterol.

Short-term intake of fresh fruit and $B$. rapa juice mixture most likely enhances cholesterol metabolism.

\section{Methods}

\section{Preparation of fresh fruit and $B$. rapa juice mixture and} commercial juice

Figure 1 shows the protocol adopted for the preparation of fresh fruit and B. rapa juice mixture. The ingredients of the juice are $B$. rapa (120 g), banana (100 g), and commercial $100 \%$ pure apple juice $(200 \mathrm{~g})$. We beat B. rapa, banana and commercial $100 \%$ pure apple juice with an electric mixer (Vitamix Model No. VM0111, VITA-MIX CORP., USA) at high speed until smooth (1 min., 37,000 rpm). Preparation of this juice mixture was on the basis of the "sanitary management of large scale cooking facilities manual [22]". Vegetable juice of the control group was a commercialized product. We prepared fresh fruit and B. rapa juice mixture every day. The commercial juice is a blend of several fruits (grape, banana, apple, lemon, and acerola) and various vegetables (carrots, sweet potatoes, lettuce, red pepper, kidney beans, kale, green pepper, Chinese cabbage, broccoli, celery, asparagus, pumpkin, komatsuna, Angelica keiskei,

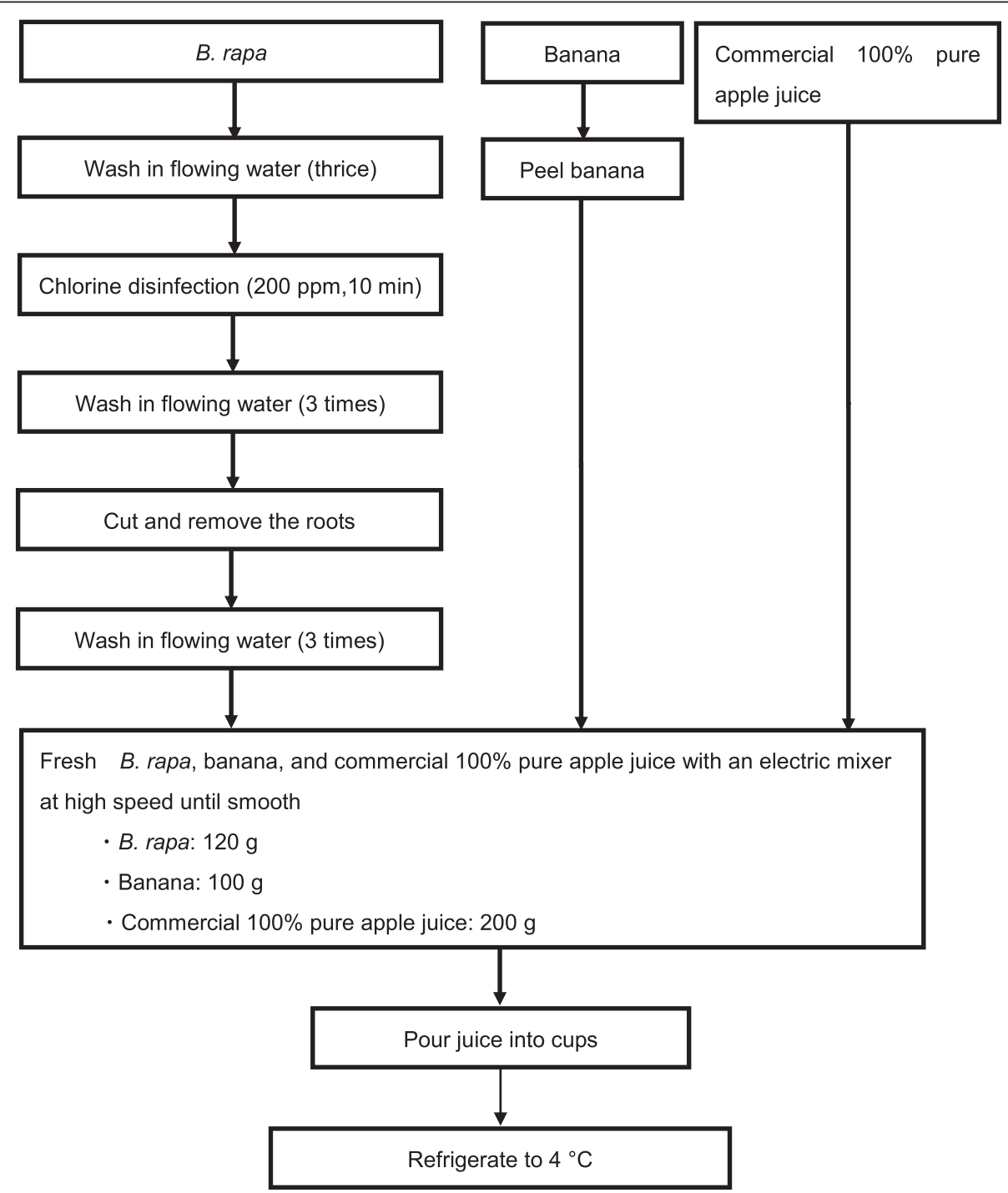

Figure 1 Preparation of fresh fruit and B. rapa juice mixture. The ingredients of the juice include B. rapa (120 g), banana (100 g), and 100\% pure, commercial apple juice $(200 \mathrm{~g}$ ). The ingredients were blended on high speed with an electric mixer (Vitamix Model No. VM0111, VITA-MIX CORP., USA) until smooth (1 min, 37,000 rpm). Preparation of the juice mixture followed the guidelines from the "sanitary management of large scale cooking facilities manual [22]. 
parsley, watercress, cabbage, radish, spinach, and Japanese honewort). It was produced by ITO EN, Ltd (trade name: ITO EN Jujitsu Yasai Banana Mix, Ito En, Ltd, Tokyo, Japan).

Nutrient components of the fresh fruit and $B$. rapa juice mixture were analyzed by Japan Inspection Association of Food and Food Industry Environment. Nutrient components of the commercial vegetable juice were noted as per the nutritional labeling on the juice package.

\section{Subjects}

Subjects were 16 worker men with a mean age of $46.4 \pm$ 7.1 years. The subjects volunteered after we described the study in great detail. The predominant work of the subjects was desk work. The physical activity level of the subjects were described as low. They were divided into two groups (control and intervention groups). One person had Grave's disease in the study, who was taking medication. However, no effect on the blood marker was found, regardless of his exclusion. Other than this subject, no other subjects took medication. This study was conducted after receiving approval from the University of Shizuoka ethics committee (No. 24-13). In this study written informed consent was obtained from all the subjects.

\section{Study design}

This study was performed for 4 weeks as a single blind, randomized controlled trial from October 30th to November 27th, 2012.

Both groups consumed juice twice a day (at 10:00 a.m. and 3:00 p.m.) every weekday. The intervention group consumed freshly prepared fruit and $B$. rapa juice mixture $(210 \mathrm{~g})$. The control group consumed a commercial vegetable juice (ITOEN JUJITSU YASAI BANANA MIX, ITO EN, LTD, Tokyo, Japan) (200 g) at the same time. The fruit and B. rapa juice mixture of the intervention group and the commercial vegetable juice of the control group were of equivalent energy content. The subjects were unaware of which juice they consumed.

\section{Anthropometric measurements and blood sampling}

Subjects fasted from 20:00 of the night before body measurements and blood collection. Height, weight, body fat percentage (BFP), waist circumference, and blood pressure were measured the following morning between 08:00 and 10:00. Body weight and BFP were measured with a body fat analyzer (TBF-215; Tanita, Tokyo, Japan). Waist circumference was measured with a tape measure at the level of the navel. Blood pressure was measured with a digital automatic sphygmomanometer (HEM-5001; OMRON, Kyoto, Japan). Waist circumference and blood pressure were measured twice each, and the mean was calculated. Blood was collected between 07:00 and 10:00.
Blood for plasma vitamin $\mathrm{C}$ analysis was collected in vacuum blood collection tubes containing sodium fluoride and dipotassium EDTA, and blood for other tests was collected in vacuum blood collection tubes containing heparin. After collection, blood collection tubes were immediately inverted and mixed, and those for other tests were left at room temperature for $30 \mathrm{~min}$ after collection. Collection tubes were then centrifuged for $15 \mathrm{~min}$ at $4^{\circ} \mathrm{C}$ and $3000 \mathrm{rpm}$. The plasma portion for vitamin $\mathrm{C}$ analysis and the serum portion for other tests were then added to microtubes and stored at $-80^{\circ} \mathrm{C}$ until analysis. Analyses of total protein, high-density lipoprotein cholesterol (HDL-Chol), LDL-Chol, triacylglycerol, free fatty acids, and hemoglobin $A_{1 c}$ were outsourced to SRL (Tokyo, Japan). Serum leptin was analyzed with a Human Leptin (Highly Sensitive) Assay Kit (ImmunoBiological Laboratories, Gunma, Japan). Serum adiponectin was analyzed with an Adiponectin Assay kit (Otsuka Pharmaceutical Co., Ltd, Japan). Plasma vitamin $\mathrm{C}$ was analyzed by the $\alpha, \alpha^{\prime}$-Dipyridyl method $[23,24]$.

\section{Food and nutrition survey}

The food and nutrition survey used was the BDHQ. The BDHQ is a 4-page fixed-portion questionnaire that asks about the consumption frequency of selected foods, but not about portion size, to estimate the dietary intake of 58 food and beverage items during the preceding month [19-21].

\section{Statistical analysis}

A normality test (Using Shapiro-Wilk test) was performed before conducting comparisons on measures before and after the intervention. When normal distribution was found, we used a paired t-test for comparisons before and after the intervention. Furthermore, a Wilcoxon signedrank test was performed when normal distribution was not found. Data were analyzed using SPSS for Windows version $15.0 \mathrm{~J}$ computer software (SPSS Japan Inc, Tokyo, Japan). Values of $p<0.05$ were accepted as significant. All values in the text and tables are represented as the mean \pm standard deviation.

\section{Abbreviations}

B. rapa: Brassica rapa L. var. perviridis; T-Chol: Total cholesterol; LDL-Chol: Low-density lipoprotein cholesterol; BMI: Body mass index; BDHQ: Brief-type self-administered diet history questionnaire; BFP: Body fat percentage; EDTA: Ethylenediaminetetraacetate; HDL-Chol: High-density lipoprotein cholesterol; HOMA-IR: Homeostasis model assessment insulin resistance.

\section{Competing interests}

The authors declare that they have no competing interest.

\section{Authors' contributions}

All authors managed the study. IA, HI and YS conducted blood analysis and dietary assessment. IA, HI, YS and TK undertook statistical analysis. IA, HI and TK drafted the manuscript. All authors read and approved the final manuscript. 


\section{Authors' information}

Laboratory of Nutrition Education, Department of Food and Nutritional Sciences and Environmental Health Sciences, Graduate School of Integrated Pharmaceutical and Nutritional Sciences, University of Shizuoka, Shizuoka 422-8526, Japan

\section{Acknowledgments}

We are grateful to subjects for participation in the study. This study was supported by the University of Shizuoka.

Received: 1 May 2014 Accepted: 17 June 2014

Published: 24 June 2014

\section{References}

1. Asia Pacific Cohort Studies Collaboration: Cholesterol, diabetes and major cardiovascular diseases in the Asia-Pacific region. Diabetologia 2007, 50:2289-2297.

2. Guimarães PR, Galvão AM, Batista CM, Azevedo GS, Oliveira RD, Lamounier RP. Freire N, Barros AM, Sakurai E, Oliveira JP, Vieira EC, Alvarez-Leite Jl: Eggplant (Solanum melongena) infusion has a modest and transitory effect on hypercholesterolemic subjects. Braz J Med Biol Res 2000, 33:1027-1036.

3. Djousse L, Arnett DK, Coon H, Province MA, Moore LL, Ellison RC: Fruit and vegetable consumption and LDL cholesterol: the National Heart, Lung, and Blood Institutte Family Heart Study. Am J Clin Nutr 2004, 79:213-217.

4. Boeing H, Bechthold A, Bub A, Ellinger S, Haller D, Kroke A, Les Chik-Bonnet E, Müller MJ, Oberritter H, Schulze M, Stehle P, Watzl B: Critical review: vegetables and fruit in the prevention of chronic diseases. Eur J Nutr 2012, 51:637-663.

5. Bazzano LA, He J, Ogden LG, Loria CM, Vupputuri S, Myers L, Whelton PK: Fruit and vegetable intake and risk of cardiovascular disease in US adults: the first National Health and Nutrition Examination Survey Epidemiologic Follow-up Study. Am J Clin Nutr 2002, 76:93-99.

6. The Ministry of Health, Labor and Welfare: Health Japan 21. http://www.dietitian.or.jp/english/images/health_japan21.pdf.

7. Shenoy SF, Kazaks AG, Holt RR, Chen HJ, Winters BL, Khoo CS, Poston WS, Haddock CK, Reeves RS, Foreyt JP, Gershwin ME, Keen CL: The use of a commercial vegetable juice as a practical means to increase vegetable intake. Nutr J 2010, 9:38.

8. Shenoy SF, Poston WS, Reeves RS, Kazaks AG, Holt RR, Keen CL, Chen HJ, Haddock CK, Winters BL, Khoo CS, Foreyt JP: Weight loss in individuals with metabolic syndrome given DASH diet counseling when provided a low sodium vegetable juice: a randomized controlled trial. Nutr J 2010, 9:8.

9. Knab AM, Nieman DC, Gillitt ND, Shanely RA, Cialdella-Kam L, Henson DA, Sha W: Effects of a flavonoid-rich juice on inflammation, oxidative stress, and immunity in elite swimmers: a metabolomics-based approach. Int J Sport Nutr Exerc Metab 2013, 23:150-160.

10. Potter AS, Foroudi S, Stamatikos A, Patil BS, Deyhim F: Drinking carrot juice increases total antioxidant status and decreases lipid peroxidation in adults. Nutr J 2011, 10:96.

11. Tiwari AK, Reddy KS, Radhakrishnan J, Kumar DA, Zehra A, Agawane SB, Madhusudana K: Influence of antioxidant rich fresh vegetable juices on starch induced postprandial hyperglycemia in rats. Food Funct 2011, 2:521-528.

12. Suido H, Tanaka T, Tabei T, Takeuchi A, Okita M, Kishimoto T, Kasayama S, Higashino K: A mixed green vegetable and fruit beverage decreased the serum level of low-density lipoprotein cholesterol in hypercholesterolemic patients. J Agric Food Chem 2002, 50:3346-3350.

13. Koike T, Liang J, Wang X, Ichikawa T, Shiomi M, Liu G, Sun H, Kitajima S, Morimoto M, Watanabe T, Yamada N, Fan J: Overexpression of lipoprotein lipase in transgenic Watanabe heritable hyperlipidemic rabbits improves hyperlipidemia and obesity. J Biol Chem 2004, 279:7521-7529.

14. Fan J, Unoki H, Kojima N, Sun H, Shimoyamada H, Deng H, Okazaki M, Shikama H, Yamada N, Watanabe T: Overexpression of lipoprotein lipase in transgenic rabbits inhibits diet-induced hypercholesterolemia and atherosclerosis. J Biol Chem 2001, 276:40071-40079.

15. Ridker PM, Danielson E, Fonseca FA, Genest J, Gotto AM Jr, Kastelein JJ, Koenig W, Libby P, Lorenzatti AJ, MacFadyen JG, Nordestgaard BG, Shepherd J, Willerson JT, Glynn RJ: Rosuvastatin to prevent vascular events in men and women with elevated C-reactive protein. N Engl J Med 2008, 359:2195-2207.
16. Itoh K, Kawasaka T, Nakamura M: The effects of high oral magnesium supplementation on blood pressure, serum lipids and related variables in apparently healthy Japanese subjects. Br J Nutr 1997, 78:737-750.

17. Fuhrman B, Elis A, Aviram M: Hypocholesterolemic effect of lycopene and beta-carotene is related to suppression of cholesterol synthesis and augmentation of LDL receptor activity in macrophages. Biochem Biophys Res Commun 1997, 233:658-662.

18. Moreno FS, Rossiello MR, Manjeshwar S, Nath R, Rao PM, Rajalakshmi S, Sarma DS: Effect of beta-carotene on the expression of 3-hydroxy-3methylglutaryl coenzyme A reductase in rat liver. Cancer Lett 1995, 96:201-208.

19. Sasaki S, Ushio F, Amano K, Morihara M, Todoriki O, Uehara Y, Toyooka E: Serum biomarker-based validation of a self-administered diet history questionnaire for Japanese subjects. J Nutr Sci Vitaminol 2000, 46:285-296.

20. Kobayashi S, Murakami K, Sasaki S, Okubo H, Hirota N, Notsu A, Fukui M, Date C: Comparison of relative validity of food group intakes estimated by comprehensive and brief-type self-administered diet history questionnaires against $16 \mathrm{~d}$ dietary records in Japanese adults. Public Health Nutr 2011, 14:1200-1211.

21. Kobayashi S, Honda S, Murakami K, Sasaki S, Okubo H, Hirota N, Notsu A, Fukui M, Date C: Both comprehensive and brief self-administered diet history questionnaires satisfactorily rank nutrient intakes in Japanese adults. J Epidemiol 2012, 22:151-159.

22. Ministry of Health, Labour and Welfare: Sanitary management of large scale cooking facilities manual (in Japanese). http://www.mhlw.go.jp/ topics/syokuchu/01.html.

23. Murata A: Plasma vitamin C concentrations of Japanese (in Japanese). Vitamins 2006, 80:513-515.

24. Murata A, Ishimatsu H, Uchi Y, Kang YC, Kato F: Determination of vitamin C by the a, a'-dipyridyl method (in Japanese). Bull Fac Agr Saga Univ 1986, $61 \cdot 9-19$

doi:10.1186/1476-511X-13-102

Cite this article as: Aiso et al: Compared with the intake of commercial vegetable juice, the intake of fresh fruit and komatsuna (Brassica rapa $\mathrm{L}$. var. perviridis) juice mixture reduces serum cholesterol in middle-aged men: a randomized controlled pilot study. Lipids in Health and Disease 2014 13:102.

\section{Submit your next manuscript to BioMed Central and take full advantage of:}

- Convenient online submission

- Thorough peer review

- No space constraints or color figure charges

- Immediate publication on acceptance

- Inclusion in PubMed, CAS, Scopus and Google Scholar

- Research which is freely available for redistribution 